\title{
Efficacy of scalp hair decontamination following exposure to vapours of sulphur mustard simulants 2-chloroethyl ethyl sulphide and methyl salicylate
}

\author{
Marie Spiandore ${ }^{\mathrm{a}}$, Anne Piram ${ }^{\mathrm{a},}{ }^{*}$, Alexandre Lacoste ${ }^{\mathrm{b}}$, Philippe Prevost ${ }^{\mathrm{c}}$, Pascal Maloni ${ }^{\mathrm{c}}$, \\ Franck Torre ${ }^{\mathrm{d}}$, Laurence Asia ${ }^{\mathrm{a}}$, Denis Josse ${ }^{\mathrm{e}}$, Pierre Doumenq ${ }^{\mathrm{a}}$ \\ a Aix-Marseille Univ, CNRS, LCE, Marseille, France \\ ${ }^{\mathrm{b}}$ Bataillon des Marins-Pompiers (BMPM) de Marseille, 13303 Marseille, France \\ c Utilis SAS, 57365 Ennery, France \\ ${ }^{\mathrm{d}}$ Institut Méditerranéen de Biodiversité et d'Ecologie Marine et continentale (IMBE), Aix-Marseille Université, CNRS, IRD, Avignon Université, Faculté de \\ Saint Jérôme, Case 421, 13397 Marseille Cedex 20, France \\ e Service Départemental d'Incendie et de Secours des Alpes-Maritimes (SDIS06), 06271 Villeneuve-Loubet Cedex, France
}

\begin{abstract}
A B S T R A C T
Chemical warfare agents are an actual threat and victims' decontamination is a main concern when mass exposure occurs. Skin decontamination with current protocols has been widely documented, as well as surface decontamination. However, considering hair ability to trap chemicals in vapour phase, we investigated hair decontamination after exposure to sulphur mustard simulants methyl salicylate and 2chloroethyl ethyl sulphide. Four decontamination protocols were tested on hair, combining showering and emergency decontamination (use of Fuller's earth or Reactive Skin Decontamination Lotion RSDL ${ }^{\circledR}$ ). Both simulants were recovered from hair after treatment, but contents were significantly reduced (42 $-85 \%$ content allowance). Showering alone was the least efficient protocol. Concerning 2-chloroethyl ethyl sulphide, protocols did not display significant differences in decontamination efficacy. For MeS, use of emergency decontaminants significantly increased showering efficacy (10-20\% rise), underlining their usefulness before thorough decontamination. Our results highlighted the need to extensively decontaminate hair after chemical exposure. Residual amounts after decontamination are challenging, as their release from hair could lead to health issues.
\end{abstract}

\section{Introduction}

Despite international regulation through the Chemical Weapons Convention [1], recent history has shown that military or civilians exposure to chemical warfare agents (CWA) can still occur [2]. Among CWA, sulphur mustard (SM or HD) is one of the most famous as it was massively used during World War I. It is a highly reactive agent which quickly penetrates skin [3] and alkylates numerous molecules, including DNA [4,5]. First symptoms of skin contamination, i.e. irritation followed by vesication, usually appear only 30 min to several hours after exposure [6].

Following exposure to CWA, emergency decontamination and

* Corresponding author. Aix Marseille Université- LCE-MPO- Europôle de l'Arbois, bât Villemin, BP80, 13545 Aix en Provence Cedex 4, France.

E-mail address: anne.piram@univ-amu.fr (A. Piram). care are of primary importance. Decontamination consists in neutralizing and/or removing the contaminant from the body surface. Emergency decontamination kits such as fuller's earth (FE) and Reactive Skin Decontamination Lotion $\left(\operatorname{RSDL}^{\circledR}\right)$ have been shown to be quite effective on pig skin when used even $45 \mathrm{~min}$ following exposure to the nerve agent VX [7]. Thorough decontamination will then consist in disrobing, showering with water containing detergent or soap, rinsing with water, and finally drying $[8,9]$.

Effectiveness of skin decontamination procedures has been largely investigated through the use of in vitro and in vivo human skin models [10-15], including human volunteers studies involving non-toxic CWA simulants $[16,17]$. However, wounds, hair or eyes decontamination have been much less studied and is important to consider. Previous studies have shown that following vapour exposure, scalp hair can trap external contaminants such as cocaine 
and cannabinoids $[18,19]$ but also the chemical warfare agent simulants methyl salicylate (MeS) [20] and 2-chloroethyl ethyl sulphide (CEES) [21]. To our knowledge, health issues related to chemicals trapping ability of hair and their subsequent decontamination have not been investigated. Indeed, once trapped in hair, chemicals could actually be released and intoxicate more people, including rescuers. As a matter of fact, secondary exposure to sarin has been observed during Tokyo subway attack in 1995 [22-24], highlighting the need for proper decontamination and protection when dealing with chemically contaminated people. Keeping that in mind, it is essential that decontamination procedures take the hair matrix into account, and that efficacy of standard decontamination protocols be evaluated for hair.

In this work, hair locks were exposed to MeS or CEES vapours, then decontaminated with various procedures in order to evaluate their efficacy on hair. These chemicals were selected as SM simulants according to their physicochemical properties. MeS shows similar vapour pressure to SM (see Table 1 ) and was then chosen to mimic SM's behaviour in vapour phase. Given that octanol/water partition coefficients are similar for both compounds (Table 1), MeS is also expected to behave similarly to SM towards the hair lipid phase. However, as opposed to MeS, the chemical structure and, as a result, electrophilic properties of CEES are similar to that of SM (Table 1). Furthermore, the main interest of using MeS as SM simulant is that it is far less toxic than SM or CEES. Therefore, it can safely be used to test experimental set-up.

Four decontamination procedures were evaluated and compared. They combined emergency decontaminants (FE and $\mathrm{RSDL}^{\circledR}$ ) and thorough decontamination (shower).

\section{Materials and methods}

\subsection{Chemicals, materials and hair}

Methyl salicylate (99\% purity), 2-chloroethyl ethyl sulphide (98\% purity) and N,O-bis(trimethylsilyl)trifluoroacetamide (BSTFA) were purchased from Sigma-Aldrich (Saint-Quentin-Fallavier, France). Internal standard (IS) methyl salicylate- $\mathrm{d}_{4}$ was purchased from Cluzeau Info Labo (Sainte-Foy-la-Grande, France). Suprasolv ${ }^{\circledR}$ dichloromethane (DCM) and acetone were supplied by VWR (Fontenay-sous-Bois, France), as well as Teflon $^{\circledR}$ ribbon used to hang hair locks for exposure.

Standard MeS $\left(1182 \mu \mathrm{g} \mathrm{mL}^{-1}\right)$ and CEES $\left(1605 \mu \mathrm{g} \mathrm{mL}^{-1}\right)$ solutions were freshly prepared in DCM, and calibration solutions were prepared by subsequent dilution of standard solutions. Preparation of spiking IS solution in acetone $\left(58.6 \mu \mathrm{g} \mathrm{mL}^{-1}\right)$ was previously described [20].
One-liter two-neck round-bottom flasks were manufactured by the glasswork service of Aix-Marseille University (Marseille, France).

FE (particle size $90 \% \leq 100 \mu \mathrm{m}$ ) was purchased from SigmaAldrich (Saint-Quentin-Fallavier, France). RSDL $^{\circledR}$ kits were obtained from E-Z-EM Canada Inc. (Anjou, Canada). The OpCell ${ }^{\circledR}$ sponge contained in those kits was cut into $2.5 \times 3.5 \mathrm{~cm}$ pieces. Liquid Marseille soap from Le Sérail (Marseille, France) was used for showering experiments. In vitro hair showering was performed as already described by Josse and colleagues [28]. Water temperature and flow rate could be modulated from 15 to $50^{\circ} \mathrm{C}$, and from 0.1 to $5 \mathrm{~L} \mathrm{~min}^{-1}$, respectively. Liquid soap concentration was adjustable from 0.2 to $10 \%$ (v/v). Absorbing paper (Fouque Chimie, Marseille, France) was used to remove FE from hair and to dry hair after showering.

Natural blond hair was supplied by Sécher-Fesnoux (Chaville, France). Hair samples were prepared as 5 -g locks ( $30-\mathrm{cm}$ long). In order to avoid hazardous chemicals projections, hair showering was performed in a CaptairPyramid glove box from Erlab (Val-deReuil, France) disposed in a fume hood.

\subsection{Hair exposure to MeS or CEES}

Hair locks were weighed then hung at the top of a 1-L closed two-neck round-bottom flasks. Pure MeS (20 $\mu$ i.e. $23.6 \mathrm{mg}$ ) or pure CEES ( $100 \mu \mathrm{L}$ i.e. $107 \mathrm{mg}$ ) was loaded at the bottom of the tank via a lateral neck. After closure, the tank was placed for $2 \mathrm{~h}$ in an oven at $40^{\circ} \mathrm{C}$ in order to speed up the evaporation process.

Control experiments were conducted in the same way. Contaminated hair was extracted just after exposure in order to evaluate initial contamination (initial content $\mathrm{Q}_{0}$ ).

\subsection{Hair decontamination}

After exposure, hair locks were removed from the tank then transferred into a crystallizer. They were subjected to decontamination according to the procedures described in the following sections. Steps combination for each procedure is detailed in Table 2.

During showering, we did not apply any physical cleaning of hair surface, i.e. use of a sponge or flannel, in order to avoid variability due to human action.

\subsubsection{Hair powdering with $F E$}

A relatively large amount of $\mathrm{FE}$, i.e. $5 \mathrm{~g}$, was poured on the hair in order to entirely cover them. Then, hair was wiped 5 times from top to bottom by using a cotton pad. This allowed enhancing FE

Table 1

Physicochemical properties and chemical structures for SM and simulants CEES and MeS.

\begin{tabular}{|c|c|c|c|}
\hline & $\begin{array}{l}\text { Sulphur mustard (SM) } \\
\text { CAS 505-60-2 }\end{array}$ & $\begin{array}{l}\text { 2-Chloroethyl ethyl sulphide (CEES) } \\
\text { CAS 693-07-2 }\end{array}$ & $\begin{array}{l}\text { Methyl salicylate (MeS) } \\
\text { CAS 119-36-8 }\end{array}$ \\
\hline Molecular mass $\left(\mathrm{g} \mathrm{mol}^{-1}\right)$ & 159.08 & 124.63 & 152.15 \\
\hline Vapour pressure $\left(\mathrm{Pa}\right.$, at $\left.25^{\circ} \mathrm{C}\right)$ & $14.1-14.7$ & 453 & $4.6-15$ \\
\hline Vapour density & $5.4-5.6$ & $4.3^{\mathrm{a}}$ & 5.2 \\
\hline $\log K_{o / w}$ & 2.41 & $2.2^{\mathrm{b}}$ & 2.55 \\
\hline Chemical structures & & & \\
\hline
\end{tabular}

\footnotetext{
Data from Refs. [6,25-27].

a Fisher Material Safety Data Sheet.

b Estimated with EPISuite v4.11 ${ }^{{ }^{2}} 2000-2012$ EPA.
} 
Table 2

Sequences of the protocols used for hair decontamination.

\begin{tabular}{|c|c|c|c|c|}
\hline & $\mathrm{RSDL}^{\circledR}+$ rinse & $\operatorname{RSDL}^{\circledR}+$ shower & $\mathrm{FE}+$ shower & Shower \\
\hline Powdering with FE (Section 2.3.1) & - & - & 1 & - \\
\hline $\begin{array}{l}\text { Application of } \text { RSDL }^{\circledR} \\
\text { (Section 2.3.2) }\end{array}$ & 1 & 1 & - & - \\
\hline $\begin{array}{l}\text { Showering and drying } \\
\text { (Section 2.3.3) }\end{array}$ & - & 2 & 2 & 1 \\
\hline 30 s rinsing with clear water & 2 & - & - & - \\
\hline
\end{tabular}

Table 3

Quantification and qualification transitions and corresponding collision energies monitored for the detection of MeS, CEES and MeS- $\mathrm{d}_{4}$ (IS).

\begin{tabular}{|c|c|c|c|c|}
\hline \multirow[t]{2}{*}{ Compound } & \multicolumn{2}{|c|}{ Quantification transition } & \multicolumn{2}{|c|}{ Qualification transition } \\
\hline & Transition $(m / z)$ & Collision energy (eV) & Transition $(m / z)$ & Collision energy $(\mathrm{eV})$ \\
\hline MeS & $209.0 \rightarrow 179.0$ & 10 & $209.0 \rightarrow 161.0$ & 20 \\
\hline CEES & $124.0 \rightarrow 75.1$ & 5 & $124.0 \rightarrow 62.0$ & 5 \\
\hline IS & $213.0 \rightarrow 183.1$ & 10 & $213.0 \rightarrow 89.0$ & 20 \\
\hline
\end{tabular}

removal from hair.

\subsection{2. $R S D L^{\circledR}$ application on hair}

$\mathrm{RSDL}^{\circledR}$ lotion $(3 \mathrm{~mL})$ was applied on the top of hair lock and then spread on the entire hair length by using an OpCell ${ }^{\circledR}$ sponge fragment $(2.5 \times 3.5 \mathrm{~cm})$. $\mathrm{RSDL}^{\circledR}$ was left on hair for $2 \mathrm{~min}$, as recommended for the skin.

\subsubsection{Hair showering and drying}

Hair showering was performed according to the ORCHIDS protocol, which is recommended for skin decontamination following exposure to CWA [29]. Hair lock was hung on top of the glove box and showered with water at $35^{\circ} \mathrm{C}$ containing $0.5 \%$ soap for $1 \mathrm{~min}$ then, after $1 \mathrm{~min}$, with clear water at $35^{\circ} \mathrm{C}$ for $1 \mathrm{~min}$ ("shower" protocol). For "RSDL ${ }^{\circledR}+$ rinse" protocol, hair was washed with clear water at $35^{\circ} \mathrm{C}$ for $30 \mathrm{~s}$. The water flow rate was $4-4.5 \mathrm{~L} \mathrm{~min}^{-1}$. After showering, hair lock was unhooked and extensively dried with absorbing paper.

\subsection{Extraction of chemicals from hair}

To extract MeS or CEES from hair, three successive solvent treatments were performed by using 50,30 and $20 \mathrm{~mL}$ dichloromethane ( $3 \times 10 \mathrm{~min}$ agitation at $250 \mathrm{rpm}$ for each treatment). Adequate dilution of pooled extracts was made before GC-MS/MS analysis.

\subsection{Gas chromatography-tandem mass spectrometry (GC-MS/MS) analysis}

MeS extracts were aliquoted to $1 \mathrm{~mL}$ and spiked with $10 \mu \mathrm{L}$ IS solution. Then, $100 \mu \mathrm{L}$ of spiked extract were transferred out to be enriched with $50 \mu \mathrm{L}$ BSTFA. They were finally heated at $55^{\circ} \mathrm{C}$ for $30 \mathrm{~min}$ to complete silylation. Derivatized extract were injected $(1 \mu \mathrm{L})$ and analysed by GC-MS/MS.

CEES extracts were directly injected and quantified with external calibration.

Extracts were analysed by gas chromatography tandem mass spectrometry. 7890A gas chromatograph and 7000 MS from Agilent Technologies, Inc. (Santa Clara, USA) were used to perform GC-MS/ MS analyses. Injection, separation and detection parameters have already been published [20]. Monitored transitions to quantify the contaminants are indicated in Table 3.

Linearity over the calibration range was satisfactory $\left(R^{2}>0.99\right)$. Calibration and control solutions were injected and accepted if back-calculation accuracies were between 80 and 120\%. Otherwise, deviant values were dismissed and corresponding samples prepared from the extracts were injected all over again.

\subsection{Decontamination efficacy}

In this work, decontamination efficacy (DE) was calculated from the ratio:

$D E(\%)=\left(\frac{Q_{0}-Q_{D}}{Q_{0}}\right) \times 100$

where $\mathrm{Q}_{0}$ is the average content of MeS or CEES extracted from nondecontaminated hair used as controls $(n=3)$ and $Q_{D}$ is the content of MeS or CEES extracted from decontaminated hair. Five replicates were performed for each decontamination protocol, and an average DE was calculated.

\subsection{Statistical analysis}

One-way between subjects ANOVA analyses were performed on decontamination efficacy data by using R software (R Core Team, R: A language and environment for statistical computing, R Foundation for Statistical Computing, Vienna, Austria). The level of significance adopted was $\mathrm{p}$-value $<0.05$ ( $\mathrm{p}<0.001$ : highly significant difference between the groups; $\mathrm{p}<0.01$ : very significant difference; $\mathrm{p}<0.05$ : significant difference; $\mathrm{p}>0.05$ : no significant differences between the groups).

\section{Results}

\subsection{Extraction of MeS or CEES from non-decontaminated hair}

Control experiments showed a recovered content of $4.21 \pm 1.38 \mu \mathrm{g} \mathrm{mg}^{-1} \mathrm{MeS}$ from non-decontaminated hair. This represented a total amount of $21 \mathrm{mg}$, namely $89 \%$ of the liquid challenge. For CEES, $1.41 \pm 0.48 \mu \mathrm{g} \mathrm{mg}^{-1}$ was extracted from nondecontaminated hair. It represented a total amount of $7 \mathrm{mg}$, namely $6.5 \%$ of the initial dose.

\subsection{Hair decontamination efficacy}

\subsection{1. $\mathrm{MeS}$}

Following decontamination, MeS extracted from hair was very significantly reduced ( $p<0.001$ ), i.e. by a 2 to 3 -fold factor 
whatever the protocol used. DE reached up to $67 \%$ when the "RSDL ${ }^{\circledR}+$ rinse" protocol was applied. The "shower" protocol was the least effective (DE value of $42 \%$ ). Application of FE or RSDL ${ }^{\circledR}$ prior to showering eliminated $52 \%$ and $65 \%$ of the contamination, respectively.

\subsubsection{CEES}

Hair decontamination was quite effective towards CEES, as all protocols reduced very significantly $(p<0.001)$ the amount of contaminant. The DE reached up to $85 \%$ when FE was used prior to showering. Showering showed $80 \%$ DE. The "RSDL ${ }^{\circledR}+$ rinse" and "RSDL ${ }^{\circledR}+$ shower" protocols yielded DE of $73 \%$ and $77 \%$, respectively. Nevertheless, there was no significant difference $(p>0.05)$ between the four tested protocols.

\subsubsection{Effect of the contaminants on the protocols $D E$}

$\mathrm{DE}$ of the four protocols against MeS and CEES are represented on Fig. 1.

The DE of "RSDL ${ }^{\circledR}+$ rinse" and "RSDL ${ }^{\circledR}+$ shower" were similar after hair exposure to MeS or CEES, i.e. about 70-80\%. By contrast, when the "FE + shower" or "shower" protocols were applied to hair, the DE was $30 \%-40 \%$ higher towards CEES than MeS.

\section{Discussion}

This study was designed to evaluate the decontamination efficacy of various standard protocols on hair exposed to CWA simulants by using an in vitro model. As it is one of the first investigations of hair decontamination, we chose to firstly evaluate existing protocols in order to establish if currently used procedures are efficient against chemically contaminated hair. For this reason, we limited our investigations to showering, FE and $\mathrm{RSDL}^{\circledR}$.

\subsection{Hair decontamination efficacy}

Hair decontamination after exposure to CWA or surrogates has been scarcely studied. Soo Hoon Eunice and colleagues showed that showering for $10 \mathrm{~s}$ with water at $21^{\circ} \mathrm{C}$ containing a cationic

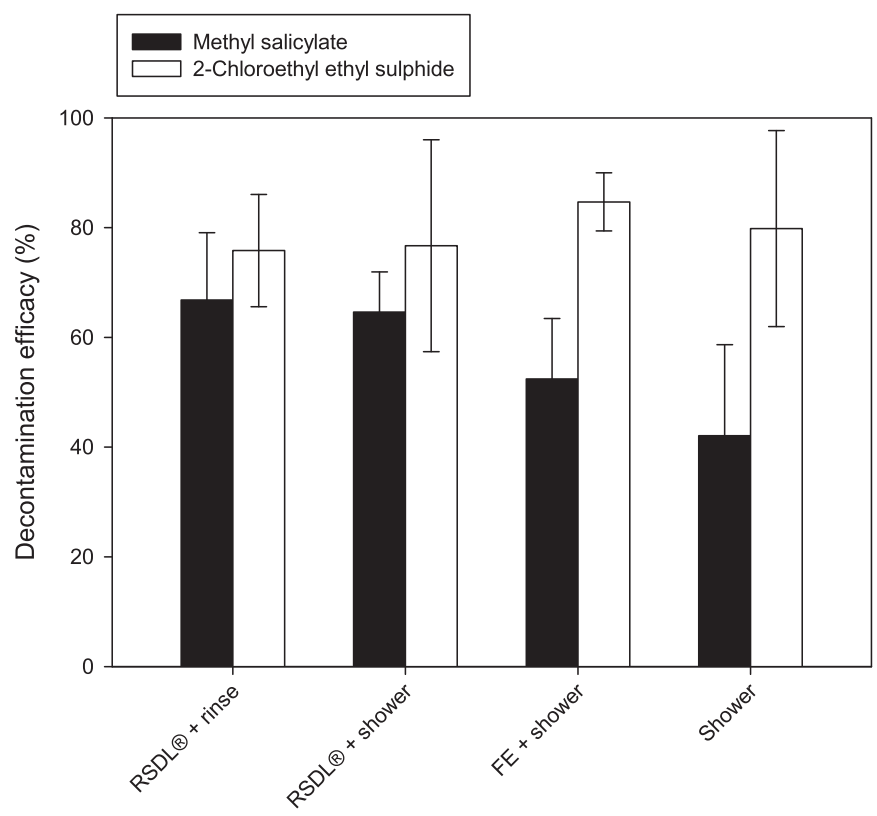

Fig. 1. Decontamination efficacy of tested protocols against hair contaminated with MeS (black) or CEES (white). surfactant only partially decontaminated hair exposed to liquid SM [30]. The maximum decontamination efficacy was 37\%. It dropped to $22 \%$ when water was used without any detergent. Thus, in this work, hair decontamination efficacy was 2 to 4 -fold lower than in our experiments. More recently, Josse et al. evaluated hair decontamination $1 \mathrm{hr}$ following liquid contamination with a droplet $(10 \mu \mathrm{L})$ of the nerve agent VX [28]. They showed that up to $98 \%$ of the initial dose could be eliminated by use of emergency decontamination (FE or $\mathrm{RSDL}^{\circledR}$ ) prior to showering.

In liquid contamination, only a small proportion of the liquid is in direct interaction with a part of the contaminated subject. On the contrary, we can reasonably assume that vapour exposure, as performed in our work, leads to a more important hair surface contamination and better mimics situations for which victims would be exposed to toxic vapours. Our results (Fig. 1) showed that hair decontamination was not $100 \%$ effective, whatever the simulant used. For MeS, up to $12 \mathrm{mg}$ was still present in $5 \mathrm{~g}$ hair after decontamination. For CEES, we quantified up to $1.9 \mathrm{mg}$ contaminant for the same amount of hair. Considering whole scalp hair on a person and depending on hair length, such residual contamination could still be significant. Residual amount of contaminant might be desorbed and transferred from hair to any surface that would come into contact with it. For SM, the percutaneous median lethal dose $\mathrm{LD}_{50 \mathrm{pc}}$ is about $100 \mathrm{mg} \mathrm{kg}^{-1}$ [25]. For a $70-\mathrm{kg}$ person, it means that $7 \mathrm{~g}$ on the skin can cause lethal effects. First irritant and/or incapacitating effects can appear at lower dose, i.e. $12-30 \mathrm{mg} \mathrm{min. \textrm {m } ^ { - 3 }}$ for vapour exposure [31], or $10 \mu \mathrm{g} \mathrm{cm}^{-2}$ for skin contact [32]. Release of trapped toxic from hair, even at the mg or $\mu \mathrm{g}$ level, could thus be health threatening for the contaminated victim and its entourage.

Our results showed that for a given procedure, DE could be agent-dependent. More specifically, the DE of hair showering with soap and water ("shower" protocol) was almost twice greater for CEES than for MeS. This could be explained by the different physicochemical properties displayed by these two agents. In particular, CEES undergoes hydrolysis faster than MeS: half-times in water are respectively $1.4 \mathrm{~min} \mathrm{[33]} \mathrm{and} 14.1$ days [26]. With protocols including water washing steps, CEES could be significantly hydrolysed, this resulting in a higher elimination rate when compared to MeS.

\subsection{Importance of emergency decontamination prior to showering}

Showering was shown to be effective for skin decontamination following exposure to SM or MeS [16,29]. In our work, showering alone proved to be the least effective procedure on SM simulant MeS (42\% DE), and for CEES ( $80 \%$ DE for showering) there was no significant difference compared to other procedures. Our study did not include hair rubbing while showering but physical action on skin surface (with the use of a flannel for example) proved to increase skin decontamination efficacy by about $20 \%$ [34].

Effectiveness of $\mathrm{FE}$ and $\mathrm{RSDL}^{\circledR}$ for skin decontamination has already been demonstrated $[7,10,35]$. In these works, FE or RSDL ${ }^{\circledR}$ were shown to significantly lower the extent of injuries and decrease the amount of agents absorbed through the skin. Moreover, work from Rolland and colleagues showed that VX contamination of hairy skin resulted in $19 \%$ of the initial dose being trapped in hair [7]. Using FE or RSDL ${ }^{\circledR}$ even 45 min after exposure respectively divided initially absorbed dose in hair by 12 and 108 . Our results confirmed the effectiveness of FE or RSDL ${ }^{\circledR}$ for hair decontamination of CEES and MeS. Hair powdering with FE prior to showering increased the decontamination efficacy of showering by about $10 \%$ for MeS and 5\% for CEES. Similarly to FE, use of $\mathrm{RSDL}^{\circledR}$ prior to showering significantly increased the hair decontamination efficacy against MeS by $23 \%$. 
When they are available, FE or $\mathrm{RSDL}^{\circledR}$ should then be recommended as emergency decontaminants of skin and hair prior to showering.

\subsection{Operational implications}

Our results together with those of previous works $[7,20,21,28,30]$ underlined the importance of taking hair into account when victims are exposed to chemicals then decontaminated.

As already demonstrated for VX [28], our results showed that when performed prior to showering, emergency decontamination, e.g. by using FE or RSDL, could significantly increase hair decontamination efficacy of SM simulants. As demonstrated for skin decontamination, our results confirmed that displacing (by adsorptive properties of decontaminants) or neutralizing (by chemical reactive reagents) the contamination plays a critical role in victims' decontamination.

\section{Conclusions}

Standard decontamination protocols were evaluated in vitro on scalp hair exposed to the SM simulants methyl salicylate (MeS) and 2-chloroethyl ethyl sulphide (CEES). Our results showed that emergency decontamination (FE or RSDL ${ }^{\circledR}$ ) prior to showering was quite effective for hair decontamination. However, decontamination efficacy did not reach $100 \%$. Residual contaminants were still removable after decontamination. Persistent contamination highlights thus the necessity to optimize hair decontamination. To that end, head shaving is not recommended since it might lead to contamination spreading and to scalp skin lesions that would enhance dermal penetration of toxicants. Indeed, hair is able to trap contaminants, but their fate in hair is not well documented. More works are thus necessary to determine whether contaminants in hair could threaten the health of the contaminated person and be transferable.

\section{Acknowledgements}

This work was financially supported by the Direction Générale de l'Armement and the Centre National de la Recherche Scientifique in France through a PhD thesis grant.

\section{References}

[1] OPCW, Convention on the Prohibition of the Development, Production, Stockpiling and Use of Chemical Weapons and on Their Destruction, 2005 (accessed 15.10.2015), http://www.opcw.org/index.php?eID=dam_frontend push\&docID $=6357$.

[2] United Nations, United Nations Mission to Investigate Allegations of the Use of Chemical Weapons in the Syrian Arab Republic, Final Report, 2013 (accessed 15.10.2015), https://unoda-web.s3.amazonaws.com/wp-content/uploads/ 2013/12/report.pdf.

[3] R.P. Chilcott, J. Jenner, W. Carrick, S.A.M. Hotchkiss, P. Rice, Human skin absorption of bis-2-(chloroethyl)sulphide (sulphur mustard) in vitro, J. Appl. Toxicol. 20 (2000) 349-355, http://dx.doi.org/10.1002/1099-1263(200009/ 10)20:5<349::AID-JAT713>3.0.CO;2-O.

[4] P.V. Lakshmana Rao, R. Vijayaraghavan, A.S.B. Bhaskar, Sulphur mustard induced DNA damage in mice after dermal and inhalation exposure, Toxicology 139 (1999) 39-51, http://dx.doi.org/10.1016/S0300-483X(99)00097-9.

[5] M.P. Shakarjian, D.E. Heck, J.P. Gray, P.J. Sinko, M.K. Gordon, R.P. Casillas, et al., Mechanisms mediating the vesicant actions of sulfur mustard after cutaneous exposure, Toxicol. Sci. 114 (2010) 5-19, http://dx.doi.org/10.1093/toxsci/ kfp253.
[6] US Department of Health and Human Services, Public Health Service, Agency for Toxic Substances and Disease Registry, Toxicological profile for sulphur mustard (HD), 2003 (accessed 4.12.2015), http://www.atsdr.cdc.gov toxprofiles/tp.asp?id=905\&tid $=184$.

[7] P. Rolland, M.-A. Bolzinger, C. Cruz, D. Josse, S. Briançon, Hairy skin exposure to VX in vitro: effectiveness of delayed decontamination, Toxicol. In Vitro 27 (2013) 358-366, http://dx.doi.org/10.1016/j.tiv.2012.08.014.

[8] A.H. Hall, H.I. Maibach, Water decontamination of chemical skin/eye splashes: a critical review, Cutan. Ocul. Toxicol. 25 (2006) 67-83, http://dx.doi.org/ 10.1080/15569520600695520.

[9] SGDN, Circulaire $n^{\circ} 700 /$ SGDN/PSE/PPS du 7 novembre 2008 relative à la doctrine nationale d'emploi des moyens de secours et de soins face à une action terroriste mettant en oeuvre des matières chimiques, 2008 (accessed 15.10.2015), http://circulaire.legifrance.gouv.fr/pdf/2009/04/cir_1349.pdf.

[10] L. Taysse, S. Daulon, S. Delamanche, B. Bellier, P. Breton, Skin decontamination of mustards and organophosphates: comparative efficiency of RSDL and Fuller's earth in domestic swine, Hum. Exp. Toxicol. 26 (2007) 135-141, http:// dx.doi.org/10.1177/0960327107071866.

[11] U. Wormser, B. Brodsky, A. Sintov, Skin toxicokinetics of mustard gas in the Guinea pig: effect of hypochlorite and safety aspects, Arch. Toxicol. 76 (2002) 517-522, http://dx.doi.org/10.1007/s00204-002-0362-6.

[12] F. Dorandeu, L. Taysse, I. Boudry, A. Foquin, F. Hérodin, J. Mathieu, et al. Cutaneous challenge with chemical warfare agents in the SKH-1 hairless mouse. (I) Development of a model for screening studies in skin decontamination and protection, Hum. Exp. Toxicol. 30 (2011) 470-490, http:// dx.doi.org/10.1177/0960327110373615.

[13] J. Misík, R. Pavliková, K. Kuča, Percutaneous toxicity and decontamination of soman, Vx, and paraoxon in rats using detergents, Arch. Ind. Hyg. Toxicol. 64 (2013) 211-217, http://dx.doi.org/10.2478/10004-1254-64-2013-2290.

14] H. Matar, A. Guerreiro, S.A. Piletsky, S.C. Price, R.P. Chilcott, Preliminary evaluation of military, commercial and novel skin decontamination products against a chemical warfare agent simulant (methyl salicylate), Cutan. Ocul. Toxicol. (2015) 1-8, http://dx.doi.org/10.3109/15569527.2015.1072544.

[15] J.-H. Sun, P.-P. Sun, W. Zheng, S. Han, Y. Ying, H.-Y, Liu, et al., Skin decontamination efficacy of potassium ketoxime on rabbits exposed to sulfur mustard, Cutan. Ocul. Toxicol. 34 (2015) 1-6, http://dx.doi.org/10.3109/ 15569527.2014 .880454

[16] D. Josse, F. Comas, J. Bui-Tho, C. Denisan, C. Cruz, R. Bifarella, et al., Comparison of showering protocols effectiveness for human volunteers' skin decontamination, Toxicol. Lett. 205 (2011) S204, http://dx.doi.org/10.1016/ j.toxlet.2011.05.701.

[17] P. Ribordy, D. Rocksén, U. Dellgar, S.-Å. Persson, K. Arnoldsson, H. Ekåsen, et al., Mobile decontamination Units-Room for improvement? Prehospital Disaster Med. 27 (2012) 425-431, http://dx.doi.org/10.1017/ S1049023X12001033.

[18] W.L. Wang, E.J. Cone, Testing human hair for drugs of abuse. IV. Environmental cocaine contamination and washing effects, Forensic Sci. Int. 70 (1995) 39-51, http://dx.doi.org/10.1016/0379-0738(94)01616-D.

[19] J. Thorspecken, G. Skopp, L. Pötsch, In vitro contamination of hair by marijuana smoke, Clin. Chem. 50 (2004) 596-602, http://dx.doi.org/10.1373/ clinchem.2003.026120.

[20] M. Spiandore, A. Piram, A. Lacoste, D. Josse, P. Doumenq, Hair analysis as a useful procedure for detection of vapour exposure to chemical warfare agents: simulation of sulphur mustard with methyl salicylate, Drug Test, Anal 6 (2014) 67-73, http://dx.doi.org/10.1002/dta.1659.

[21] M. Spiandore, A. Piram, A. Lacoste, D. Josse, P. Doumenq, P6: hair desorption of the sulphur mustard simulants methyl salicylate and 2-chloroethyl ethyl sulfide following vapour exposure, Toxicol. Anal. Clin. 26 (2014) S33, http:// dx.doi.org/10.1016/S2352-0078(14)70067-8.

[22] H. Nozaki, S. Hori, Y. Shinozawa, S. Fujishima, K. Takuma, M. Sagoh, et al. Secondary exposure of medical staff to sarin vapor in the emergency room Intensive Care Med. 21 (1995) 1032-1035, http://dx.doi.org/10.1007/ BF01700667.

[23] T. Okumura, K. Suzuki, A. Fukuda, A. Kohama, N. Takasu, S. Ishimatsu, et al., The Tokyo subway sarin attack: disaster management, part 1: community emergency response*, Acad. Emerg. Med. 5 (1998) 613-617, http://dx.doi.org 10.1111/j.1553-2712.1998.tb02470.x.

[24] T. Okumura, K. Suzuki, A. Fukuda, A. Kohama, N. Takasu, S. Ishimatsu, et al. The Tokyo subway sarin attack: disaster management, part 2: hospital response*, Acad. Emerg. Med. 5 (1998) 618-624, http://dx.doi.org/10.1111/ j.1553-2712.1998.tb02471.x.

[25] K. Ganesan, S.K. Raza, R. Vijayaraghavan, Chemical warfare agents, J. Pharm. Bioallied Sci. 2 (2010) 166-178, http://dx.doi.org/10.4103/0975-7406.68498.

[26] National Institute of Health, HSDB: Methyl Salicylate, 2003 (accessed 25.9.2015), http://toxnet.nlm.nih.gov/cgi-bin/sis/search2/r?dbs+hsdb:@ term+@DOCNO+1935.

[27] D.R. Lide (Ed.), CRC Handbook of Chemistry and Physics, Internet Version 2005, CRC Press, Boca Raton, FL, 2005. http://www.hbcpnetbase.com.

[28] D. Josse, J. Wartelle, C. Cruz, Showering effectiveness for human hair decontamination of the nerve agent VX, Chem. Biol. Interact. 232 (2015) 94-100, http://dx.doi.org/10.1016/j.cbi.2015.03.010.

[29] R. Amlôt, L. Riddle, J. Larner, R. Jones, M. Hiley, J. Egan, et al., Evaluation, Optimisation, Trialling and Modelling of Procedures for Mass Casualty Decontamination (ORCHIDS), Final report for implementation phase (2011) http://www.orchidsproject.eu/. 
[30] S. Soo Hoon Eunice, C.S. Ling, T.G. Sze, Study of Effects of Parameters on Personnel Decontamination, Poster presented at Decon S\&T Conference, Lake Louise, Canada (2010).

[31] Subcommittee on Acute Exposure Guideline Levels, Committee on toxicology board on environmental studies and toxicology, in: Acute Exposure Guideline Levels for Selected Airborne Chemicals, Volume 3, The National Academies Press, Washington, D.C., 2003 (accessed 12.10.2015), http://www.nap.edu/ catalog.php?record_id=10672.

[32] I.J. Hattersley, J. Jenner, C. Dalton, R.P. Chilcott, J.S. Graham, The skin reservoir of sulphur mustard, Toxicol. In Vitro 22 (2008) 1539-1546, http://dx.doi.org/ 10.1016/j.tiv.2008.06.002
[33] Y.C. Yang, L.L. Szafraniec, W.T. Beaudry, J.R. Ward, Kinetics and mechanism of the hydrolysis of 2-chloroethyl sulfides, J. Org. Chem. 53 (1988) 3293-3297, http://dx.doi.org/10.1021/jo00249a029.

[34] R.P. Chilcott, Managing mass casualties and decontamination, Environ. Int. 72 (2014) 37-45, http://dx.doi.org/10.1016/j.envint.2014.02.006.

[35] L. Taysse, F. Dorandeu, S. Daulon, A. Foquin, N. Perrier, G. Lallement, et al., Cutaneous challenge with chemical warfare agents in the SKH-1 hairless mouse (II): effects of some currently used skin decontaminants (RSDL and Fuller's earth) against liquid sulphur mustard and VX exposure, Hum. Exp. Toxicol. 30 (2011) 491-498, http://dx.doi.org/10.1177/0960327110373616. 